\title{
Analysis of internal crack in a six-ton P91 ingot
}

\author{
Jing-an Yang', *Hou-fa Shen', Bai-cheng Liu', Ya-dong $\mathrm{Xu}^{2}$, Yong-ping $\mathrm{Hu}^{2}$, and Bing-wang Lei ${ }^{2}$ \\ 1. School of Materials Science and Engineering, Tsinghua University, Beijing 100084, China \\ 2. Special Material Institute, Inner Mongolia North Heavy Industries Group Co., Ltd., Baotou 014033, China
}

\begin{abstract}
P91 is a new kind of heat-resistant and high-tensile steel. It can be extruded after ingot casting and can be widely used for different pipes in power plants. However, due to its mushy freezing characteristics, a lack of feeding in the ingot center often generates many defects, such as porosity and crack. A six-ton P91 ingot was cast and sliced, and a representative part of the longitudinal section was inspected in more detail. The morphology of crack-like defects was examined by X-ray high energy industrial CT and reconstructed by $3 \mathrm{D}$ software. There are five main portions of defects larger than $200 \mathrm{~mm}^{3}$, four of which are interconnected. These initiated from continuous liquid film, and then were torn apart by excessive tensile stress within the brittle temperature range (BTR). The 3D FEM analysis of thermo-mechanical simulation was carried out to analyze the formation of porosity and internal crack defects. The results of shrinkage porosity and Niyama values revealed that the center of the ingot suffers from inadequate feeding. Several criteria based on thermal and mechanical models were used to evaluate the susceptibility of hot crack formation. The Clyne and Davies' criterion and Katgerman's criterion successfully predicted the high hot crack susceptibility in the ingot center. Six typical locations in the longitudinal section had been chosen for analysis of the stresses and strains evolution during the BTR. Locations in the defects region showed the highest tensile stresses and relative high strain values, while other locations showed either low tensile stresses or low strain values. In conclusion, hot crack develops only when stress and strain exceed a threshold value at the same time during the BTR.
\end{abstract}

Key words: hot crack; industrial CT; liquid film; thermo-mechanical simulation; steel ingot
CLC numbers: TG142.73
Document code: $A$
Article ID: 1672-6421(2016 03-191-08

$\mathrm{I}$ nternal crack of an ingot is frequently encountered in casting practice, which directly leads to scrapping the whole product. From many studies ${ }^{[1-7]}$, it appears that hot crack initiates in the brittle temperature range and propagates in the interdendritic liquid film. An extension of the two-phase model, which includes plasticity of the porous network, is reported, considering the void as the crack nucleus, although the pores should not necessarily develop into a crack ${ }^{[8]}$. The crack may nucleate or develop from other defects and then propagate through a chain of pores. The excessive stress and strain developing during the brittle temperature range are the main reasons for hot crack formation. A coherent dendritic network can sustain and transmit stress. Above the coherency temperature, continuous liquid film still exists as the solid dendrite arms have not yet coalesced. Deformation induced by thermal stress can pull these

\footnotetext{
*Hou-fa Shen

Male, born in 1964, Ph.D., Professor. Research interests: modeling and simulation of the solidification process related to conventional casting, ingot casting and continuous casting.

E-mail: shen@tsinghua.edu.cn
}

Received: 2015-12-21; Accepted: 2016-03-02 arms apart quite easily. However, deep in the mushy zone, where the permeability of the mush is very low, and the opening of the non-coherent dendritic network by tensile deformation cannot be compensated by liquid feeding, hot crack forms ${ }^{[9]}$.

So it is essential to investigate the stress and strain evolution in the brittle temperature range when the mush is vulnerable to tensile deformation. Since the 1960s, criteria for hot crack based on thermal considerations and solid mechanics are the primary means to evaluate the hot crack formation. Some criteria are based only on thermal considerations as Clyne and Davies's criterion ${ }^{[10]}$ and Katgerman's criterion ${ }^{[11]}$, while some criteria are based on both thermal and mechanical considerations, such as Guo's criterion ${ }^{[12]}$ and WYSO's criterion ${ }^{[3]}$.

In practice, internal crack was found in P91 ingot, which was extruded to produce heat-resistant pipes for a power station. It is known that P91steel has a larger freezing range, i.e., $183 \mathrm{~K}$ between the liquidus and solidus, and it is estimated that hot crack forms because such an alloy spends a longer time in the vulnerable state in which thin liquid films exist between the dendrites ${ }^{[13]}$. The mushy zone behavior is very complex, considering feeding, coalescence, deformation, etc. Much effort 
should be paid to predict hot crack formation. Therefore, a 6-ton P91 ingot was cast and sliced to analyze the formation of internal crack for this study.

\section{Experimental procedure}

A bottom-poured 6-ton P91 ingot was sliced after solidification to ascertain the internal quality. The ingot body is hexadecagon with a height of $1315 \mathrm{~mm}$, bottom diameter $690 \mathrm{~mm}$ and top diameter $858 \mathrm{~mm}$. Composition of P91 grade steel is shown in Table 1.

Table 1: Chemical composition of P91 grade steel (wt.\%)

$\begin{array}{ccccccccc}\text { C } & \text { Si } & \text { Mn } & \mathbf{V} & \mathbf{C r} & \text { Mo } & \mathbf{N} & \text { Nb } & \text { Fe } \\ 0.08 & 0.2 & 0.3 & 0.18 & 8 & 0.9 & 0.03 & 0.06 & \text { Bal. }\end{array}$

Figure 1(a) shows the sliced ingot, which was cut into three parts in height at a distance of $350 \mathrm{~mm}$ and $940 \mathrm{~mm}$ from the ingot bottom, respectively. Then the middle part of the ingot was split from the center plane and a longitudinal section off the center plane $90 \mathrm{~mm}$ was obtained as shown in Fig. 1(b). After polishing, it was found that the crack-like defects concentrated in the center of the upper part of the longitudinal section. A mapping of internal cracks is schematically illustrated in Fig. 1(b).

A rectangular block containing crack-like defects with height of $280 \mathrm{~mm}$, width of $120 \mathrm{~mm}$ and thickness of $90 \mathrm{~mm}$ was sliced again and examined by X-ray high energy industrial CT as shown in Fig. 1(c). In order to adapt the X-ray penetration ability, the rectangular block (Fig. 1c) was further cut into three long bars with dimension of $28 \mathrm{~mm} \times 28 \mathrm{~mm} \times 200 \mathrm{~mm}$ (Fig. 3a). The front view of the first long bar is shown in Fig. 2a. Figures $2 b-2 i$ are CT images at the depth gradually penetrating from the front to the back of the bar. It can be imaged that the cracks stretch in the ingot body as bending sheets. In order to gain an overall view, defects in the three long bars were reconstructed according to the obtained CT images (Fig. 3b), where the color indicator represents defect volume. Superficially, the defects are fragmentary but actually, they are more continuous than expected. The total volume of the defects in three bars are $1864.71 \mathrm{~mm}^{3}, 498.52 \mathrm{~mm}^{3}, 682.59 \mathrm{~mm}^{3}$, about $1.39 \%$, $0.37 \%, 0.5 \%$ of the entity, respectively. There are five main portions of defects greater than $200 \mathrm{~mm}^{3}$ in Fig. 3(b), where the color is remarked with red, pink, and green. The blue marks show the remaining small defects below $50 \mathrm{~mm}^{3}$, which may be micro-cracks or porosities. Through recombining the three $\mathrm{CT}$ reconstructions, as shown in Fig. 3(c), it is found that most defects connect with each other, especially the four main defects greater than $200 \mathrm{~mm}^{3}$ on the upper part of the bars. The connected defects derived from continuous liquid films. As the solidification progresses, inadequate feeding and tensile deformation created the opening of the non-coherent dendrite network and induced hot crack formation.

Fig. 1: (a) Schematic of sliced ingot, (b) slice in longitudinal section of ingot, (c) rectangular block cut from the slice

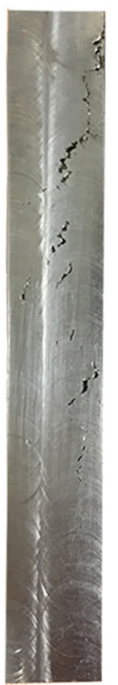

(a)

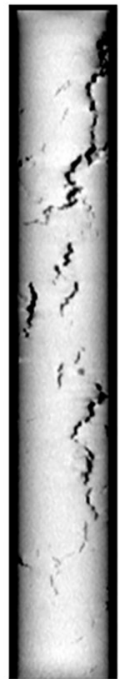

(b)

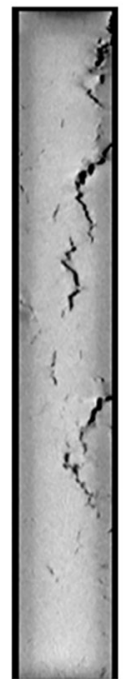

(c)

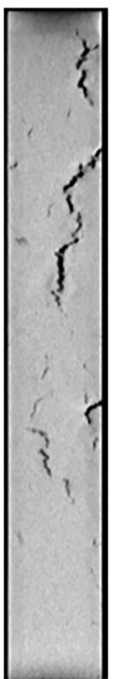

(d)

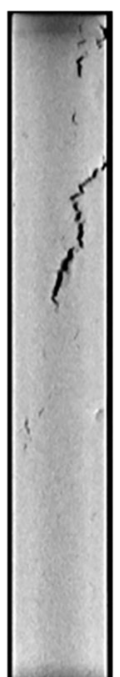

(e)

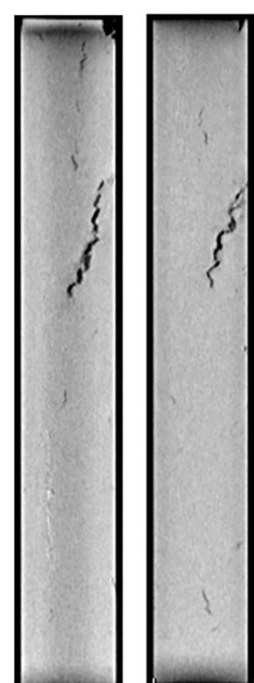

(f)

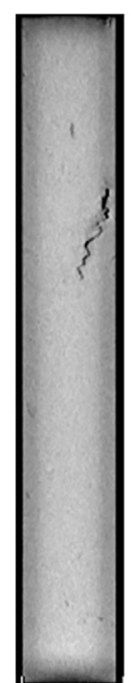

(h)

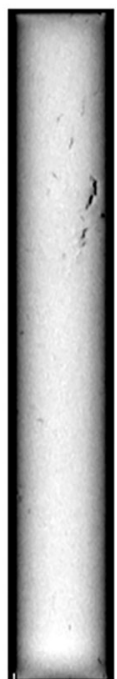

(i)

Fig. 2: (a) Front view of first long bar, (b)-(i) CT images at the depth gradually penetrating from the front to the back of bar 


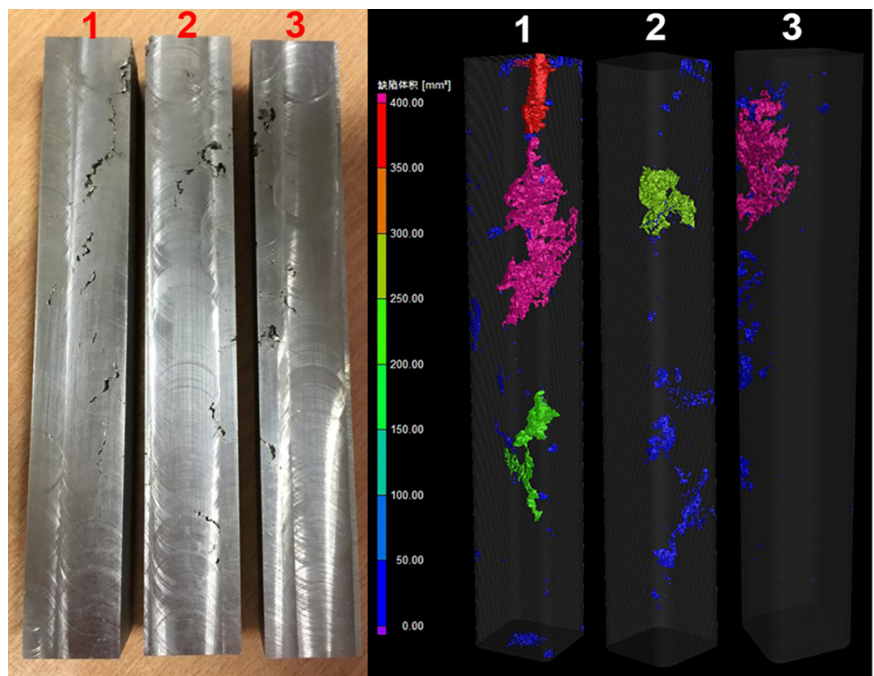

(a) (b)

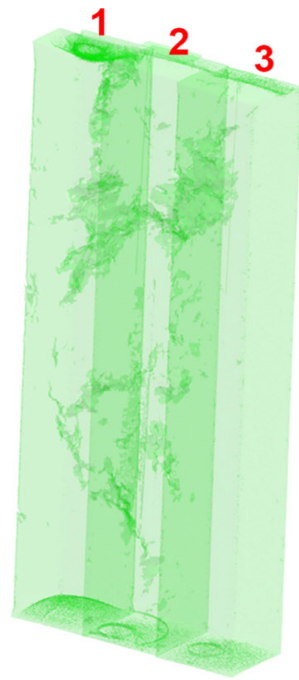

(c)

Fig. 3: (a) Three long bars from the rectangular block (Fig. 1c), (b) 3D CT image reconstruction with transparent display, (c) recombination of three CT reconstructions

\section{Numerical simulation}

The 3D FEM analysis of temperature field and stress field was carried out based on ProCAST software. An FEM mesh including the ingot and mold system (Fig. 4a) with $2,638,787$ elements was generated for the calculation as shown in Fig. 4(b). The thermophysical properties, such as thermal conductivity, density, enthalpy, and fraction solid are calculated by CompuTherm thermodynamic database for multicomponent Fe-rich alloys of ProCAST. At the same time, the thermomechanical properties, such as Young's Modulus, Poisson's Ratio, yield stress, thermal expansion and plastic modulus are calculated by General Steel database of JMatPro. The stress type of the casting is Elasto-plastic and hardening type is linear isotropic.

Shrinkage porosity within the mushy zone including microporosity, macro-porosity and pipe-shrinkage formation during solidification was predicted using a dynamic refinement

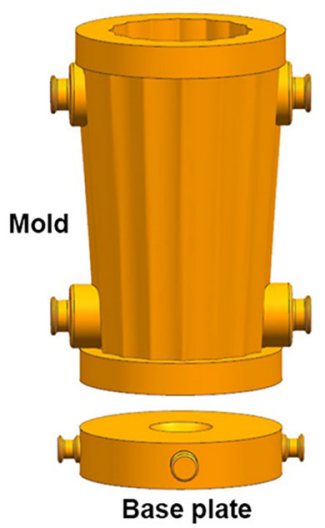

(a)

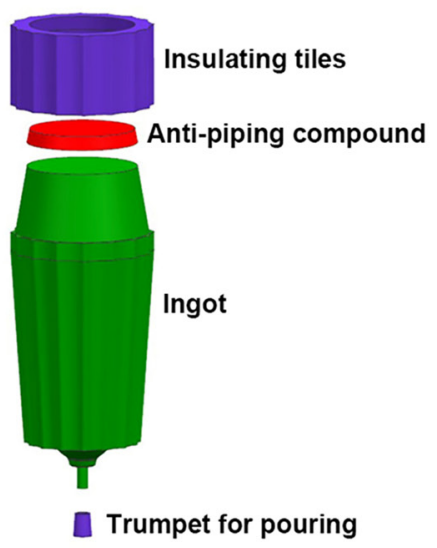

Trumpet for pouring

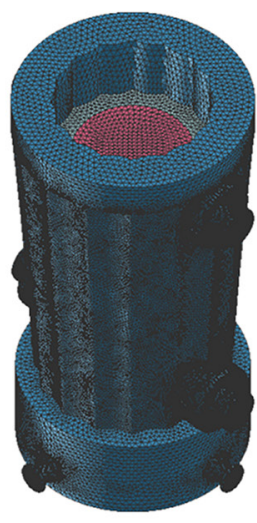

(b) where $h$ is the adjusted heat transfer coefficient, $h_{0}$ is the initial value of the heat transfer coefficient, $P$ is the contact pressure, $A$ is an empirical constant accounting for contact pressure.

Data of model information, temperature field evolution, isochrones of different solid fractions, principal stresses and strains evolution in three directions, and cooling rate information were extracted from the final results of ProCAST and then processed by $\mathrm{C}++$ programming to evaluate the hot crack susceptibility using different criteria, such as Clyne and Davies

criterion, Katgerman's criterion, and WYSO's criterion.

Clyne and Davies' criterion ${ }^{[10]}$ considers that in the last stage of solidification, it is difficult for the liquid to move freely so that the strains developed during this stage cannot be accommodated by the mass feeding and liquid feeding. The cracking susceptibility is defined by the ratio of the vulnerable time period where hot tearing may develop, $t_{V}$, and time available for the stressrelief process where mass feeding and liquid feeding occur, $t_{R}$. The cracking susceptibility coefficient HCS reads:

Fig. 4: (a) Geometry characteristic of ingot and mold system, (b) 3D FEM mesh 


$$
H C S=\frac{t_{V}}{t_{R}}=\frac{t_{0.99}-t_{0.9}}{t_{0.9}-t_{0.4}}
$$

where $t_{0.99}$ is the time when the volume fraction of solid, $f_{\mathrm{s}}$, is 0.99 , $t_{0.9}$ is the time when $f_{\mathrm{s}}$ is 0.9 , and $t_{0.4}$ is the time when $f_{\mathrm{s}}$ is 0.4 .

Katgerman's criterion ${ }^{[10]}$ defines the hot tearing index, HCS, as follows:

$$
H C S=\frac{t_{0.99}-t_{c r}}{t_{c r}-t_{c o h}}
$$

where $t_{0.99}$ is the time when the volume fraction of solid, $f_{\mathrm{s}}$, is 0.99 , $t_{c o h}$ is the time when $f_{\mathrm{s}}$ is at the coherency point, and $t_{c r}$ is the time when feeding becomes inadequate.

Guo's criterion ${ }^{[12]}$ is a hot tearing indicator of ProCAST, which is based on the accumulated plastic strain in the last stage of solidification, as follows:

$$
e_{h t}=\int_{t_{c}}^{t} \sqrt{(2 / 3) \dot{\varepsilon}^{P} \dot{\varepsilon}^{P}} d \tau \quad t_{c} \leq t \leq t_{s}
$$

where $t_{c}$ represents time at coherency temperature and $t_{s}$ denotes time at solidus temperature.

WYSO's criterion ${ }^{[3]}$ compares the accumulated strain undergone by the material over the brittle temperature range to a given strain limit. It is expressed as follows:

$$
H C C_{\text {WYSO }}=\operatorname{Max}_{B T R}\left(\int \hat{\dot{\varepsilon}}(t) d t-\hat{\varepsilon}_{c}\right) \text { with } \hat{\varepsilon}_{c}=\frac{\varphi}{(\hat{\dot{\varepsilon}})^{m^{*}} B T R^{n^{*}}}
$$

where, the three parameters have been deduced by a nonlinear data fitting covering numerous tests performed on different midalloyed steel grades: $\varphi=0.02821, m^{*}=0.3131$, and $n^{*}=0.8638$.

\section{Results and discussion}

The simulated results of shrinkage porosity in the longitudinal section of the ingot are shown in Fig. 5(a). The red horizontal lines in Fig. 5 represent the transverse cutting positions of the ingot (Fig. 1a). As can be seen from the figure, pipeshrinkage forms in the riser of the ingot, and micro-porosity and macro-porosity form mostly along the center line of the ingot, especially in the upper part of the ingot and the bottom of the pipe (i.e., the primary shrinkage cavity). The shrinkage porosities in excess of $2 \%$ are composed mainly of macroporosity, which form a narrow band in the center of the ingot, indicating a lack of melt feeding. The Niyama values under $8(\mathrm{~K} \cdot \mathrm{S})^{0.5} \cdot \mathrm{cm}^{-1}$ in Fig. 5 (b) show a strong possibility of porosity as well.

Hot crack susceptibility was evaluated as shown in Fig. 6. Figures 6(a) and 6(b) are hot crack susceptibilities according to Clyne and Davies' criterion and Katgerman's criterion, respectively. They are based only on thermal considerations, mainly taking into account the time spent in a vulnerable state, during which hot crack may develop. They both successfully predicted the high hot crack susceptibility in the ingot center, but additionally showed high susceptibility along the ingot surface, which was not found in the experiment. There are certain limitations when only considering temperature evolution. By thermo-mechanical calculation, treating the ingot body as an Elasto-plastic model, Guo's criterion and WYSO's criterion are tried, but they both show low hot crack susceptibility in the ingot center. The main reason may be that the two criteria are in essence strain-based criteria and the critical strain is treated as a global constant regardless of porosity formation due to inadequate liquid feeding, mush zone embrittlement due to detrimental elements enrichment, coarse grain due to low undercooling degree, and so on. Additionally, high strain under low stress does not necessarily lead to hot crack formation.

Thermo-mechanical simulation was used to provide a detailed description of the evolution of stresses and strains during the ingot solidification. Six typical locations in the longitudinal section have been chosen for analysis and comparison as shown in Fig. 7(a). Locations A, B, C, D are in the center line of the ingot and locations $\mathrm{E}, \mathrm{F}$ are in the radial direction, relative positions of which have been labeled in Fig. 7(a). Minimum and maximum stress, strain, and time duration within the brittle temperature range at the six locations are listed in Fig.7(b). Brittle temperature range is between liquid impenetrable temperature (LIT) and zero ductility temperature (ZDT). The corresponding solid fractions for LIT and ZDT are

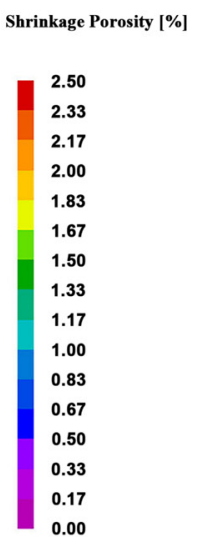

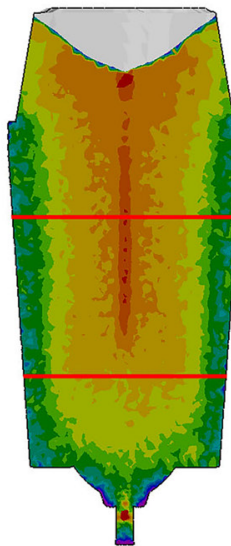

(a)

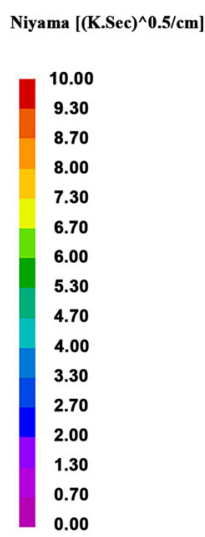

(b)

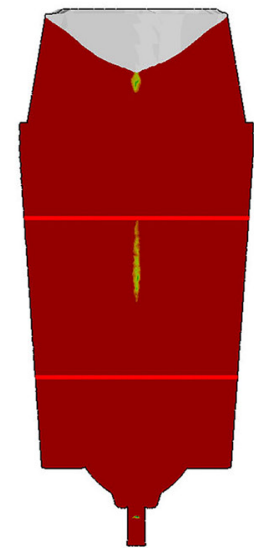

Fig. 5: (a) Shrinkage porosity in the longitudinal section of ingot, (b) Niyama values in the longitudinal section of ingot 
0.9 and 0.99 , respectively ${ }^{[15]}$. First, principal stresses and strains are the main indicator for evaluation of stress-strain state. Their detailed evolution with temperature change is shown in Figs. 8 and 9, respectively. In Fig. 8, horizontal axis shows time, left vertical axis shows temperature and right vertical axis shows first principal stress. In Fig. 9, only the right vertical axis changes to first principal strain compared to Fig. 8 . The dashed blue horizontal lines in the two figures are used to indicate BTR zone, i.e., temperature between LIT and ZDT when solid fractions are 0.9 and 0.99 , respectively.

Location A as shown in Fig. 7(a) is on the top center of the slice of the longitudinal section (Fig. 1b), where the most severe defects were found. 1,300 seconds is spent within the BTR and the maximum stress and strain develop up to $80 \mathrm{MPa}$ and 0.0016 , respectively. Location $\mathrm{B}$ is also located in the defects area, but the degree is much less severe. The time spent within BTR is 1,200 seconds and the maximum stress and strain develop up to $70 \mathrm{MPa}$ and 0.001 , respectively, which are both less than the corresponding value of location $\mathrm{A}$. Location $\mathrm{C}$ is below the defects area, where no defects were found. 1,000 seconds are spent within the BTR and the maximum stress and strain develop up to $70 \mathrm{MPa}$ and 0.0008 , respectively. Compared to location $\mathrm{B}$, the maximum stress is the same but the maximum strain and time duration within BTR are both less, which makes the area less susceptible to hot crack. Location D is even much lower than the defects range and on the bottom center of the slice. Compared

to location $\mathrm{C}$, time duration within BTR is 100 seconds less, and the maximum stress is $40 \mathrm{MPa}$, much less than $70 \mathrm{MPa}$. The strain develops from 0.00014 to 0.00033 , much less than 0.0008 . For these reasons, it is more likely that the hot crack will not develop.

Location $\mathrm{E}$ is on the top of slice and $215 \mathrm{~mm}$ from the center (location A), where defects were also not found. Time duration within the BTR is rather long and up to 2,400 seconds, but the stress is in the compress state when temperature begins to fall in the BTR range and then develops to tensile stress and up to $15 \mathrm{MPa}$, which is relatively a very small tensile stress for dendrite network detachment. The strain develops from 0.0005 to 0.0035 , which is a relatively high value. But it did not result in hot crack because there is enough time to generate elastic-plastic deformation under a low tensile stress. Meanwhile, this explains the overestimation of hot crack susceptibility by strain-based criteria. Location $\mathrm{F}$ is near the

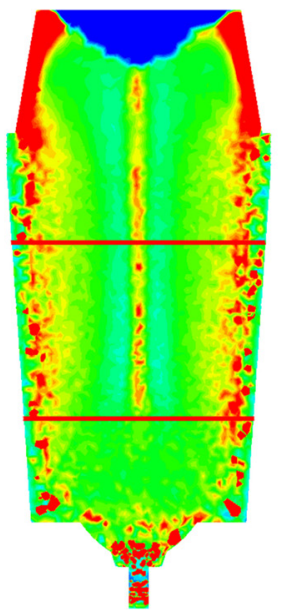

(a)

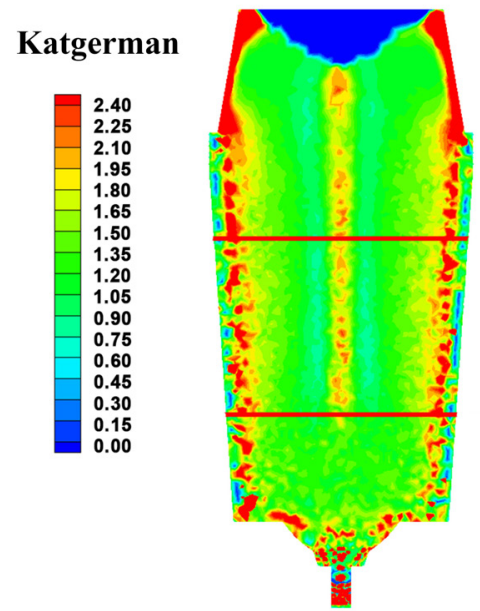

(b)
Fig. 6: (a) Hot crack susceptibilities (HCS) according to Clyne and Davies's criterion, (b) HCS according to Katgerman's criterion

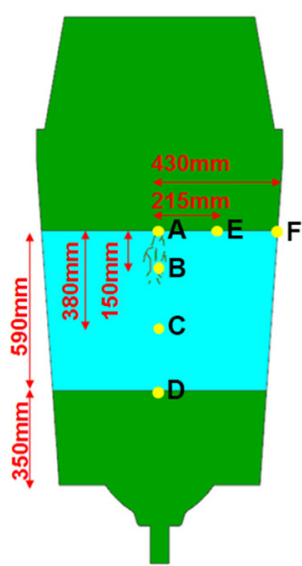

(a)

\begin{tabular}{|c|c|c|c|c|}
\hline \multicolumn{2}{|c|}{ BTR } & Stress(MPa) & Strain & Time(s) \\
\hline \multirow{2}{*}{ A } & $\min$ & 0 & 0 & \multirow{2}{*}{1300} \\
\hline & $\max$ & 80 & 0.0016 & \\
\hline \multirow{2}{*}{ B } & $\min$ & 0 & 0 & \multirow{2}{*}{1200} \\
\hline & $\max$ & 70 & 0.001 & \\
\hline \multirow{2}{*}{ C } & $\min$ & 0 & 0 & \multirow{2}{*}{1000} \\
\hline & $\max$ & 70 & 0.0008 & \\
\hline \multirow{2}{*}{ D } & $\min$ & 0 & 0.00014 & \multirow{2}{*}{900} \\
\hline & $\max$ & 40 & 0.00033 & \\
\hline \multirow{2}{*}{$E$} & $\min$ & -5 & 0.0005 & \multirow{2}{*}{2400} \\
\hline & $\max$ & 15 & 0.0035 & \\
\hline \multirow{2}{*}{$\mathbf{F}$} & $\min$ & 0 & 0 & \multirow{2}{*}{14} \\
\hline & $\max$ & 16 & 0.0008 & \\
\hline
\end{tabular}

(b)
Fig. 7: (a) Six locations of interest in the longitudinal section of ingot, (b) minimum and maximum stress, strain, and time duration of six locations under solidification within BTR

ingot surface, where is free from defects. Due to the chilling effect of the ingot mold, its time duration within the BTR is only 14 seconds and the maximum stress and strain develop up to $16 \mathrm{MPa}$ and 0.0008 , respectively, which are both relatively low values for hot crack formation. Because of the shortness of time duration within the BTR, the criteria based only on thermal considerations, such as Clyne and Davies' criterion and Katgerman's criterion, are not so precise in predicting hot crack in the ingot chill zone.

Equivalent strain and stress in the longitudinal section within the BTR are shown in Fig. 10. Although the equivalent strain of the defects zone is relatively small, there are many factors leading to hot crack, such as inadequate feeding (Fig. 5), detrimental elements enrichment, excessive stress (Fig. 10b), and so on. Figure 11 shows the main simulation results compared with the experiment, where Fig. 11(a) schematically illustrates the experiment results of the crack- 

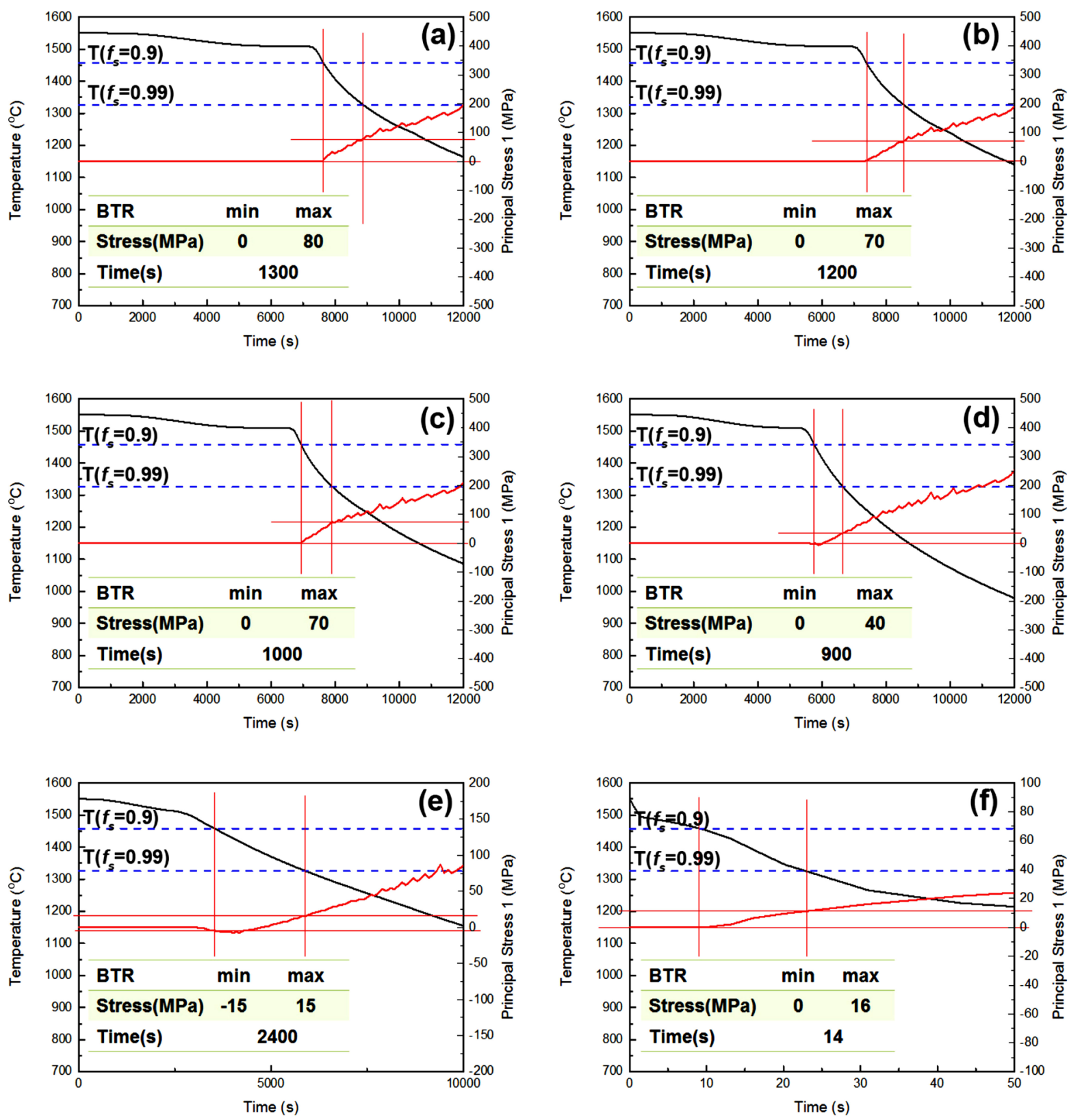

Fig. 8: Temperature and first principal stress evolution in locations A-F as shown in Fig. 7(a)

like defects. Figures 11(b) and 11(c) reveal that the centerline of the ingot suffers inadequate feeding by shrinkage porosity and Niyama values respectively; Figure 11(d) indicates that the defects region is under excessive tensile stress within the BTR; Figures 11(e) and 11(f) suggest that the centerline of the ingot has the highest hot crack susceptibility. Above all, these factors cause the opening of the non-coherent dendrite network and incur pores nucleation, growth and interaction for crack formation

\section{Conclusion}

The internal defects of a 6-ton P91 ingot were characterized by X-ray high energy industrial CT and 3D CT image reconstruction. It was found that the defects are distributed in the upper center part of the ingot and mainly composed of hot cracks, which derive from continuous liquid film and develop under tensile stress when the mush is vulnerable, i.e., within the brittle temperature range (BTR). Thermo-mechanical calculation by 3D FEM analysis based on ProCAST software was carried out and relative data were extracted and then processed by $\mathrm{C}++$ programming to evaluate the hot crack susceptibility. Four criteria were used, two based only on thermal considerations and the others based both on thermal and mechanical considerations. The first two, Clyne and Davies's criterion and Katgerman's criterion, both successfully predicted the high hot crack susceptibility in the ingot center, but were not precise in the ingot chill zone. The latter two, Guo's criterion and WYSO's criterion both strain-based criteria, indicated low hot crack susceptibility in the ingot center.

The stresses and strains evolution and equivalent stress and 

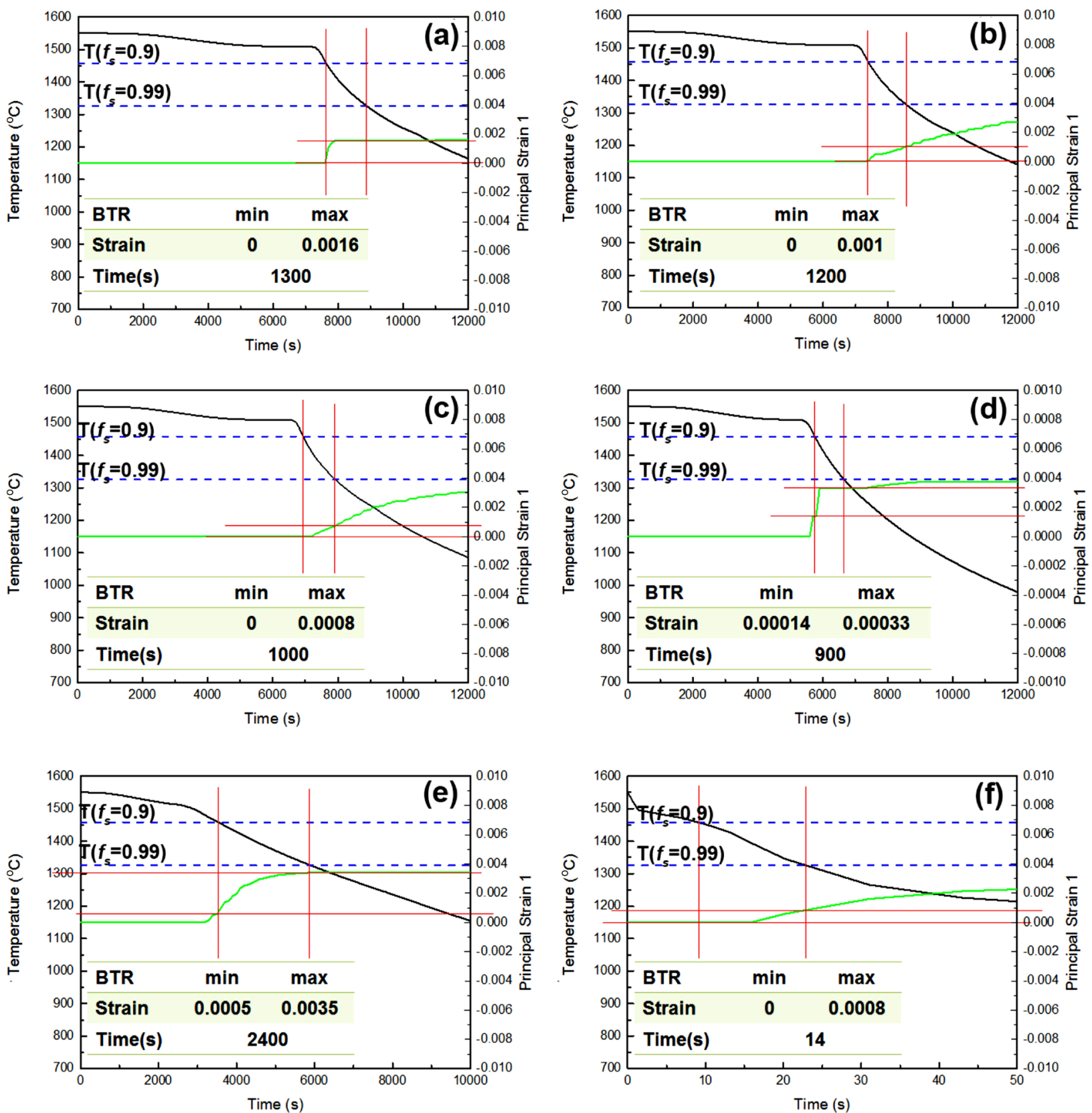

Fig. 9: Temperature and principal strain in locations A-F as shown in Fig. 7(a)

strain development in the longitudinal section of ingots show that the stress exceeds the limits of non-coherent dendrite network, and then the strain develops over a critical value to initiate hot cracks. The critical value for strain should be an adaptive value considering the diversity of different parts of the ingot, such as porosity formation due to inadequate liquid feeding, mush zone embrittlement due to detrimental elements enrichment, coarse grain due to low undercooling degree, and so on. Therefore, more efforts should be made on numerical simulation to predict hot crack formation, considering the above mentioned factors and other relevant mechanisms.

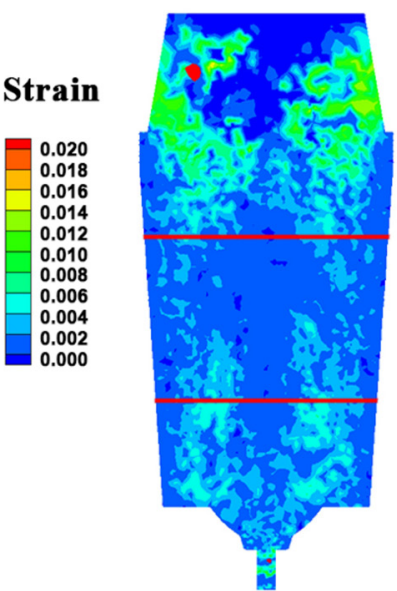

(a)

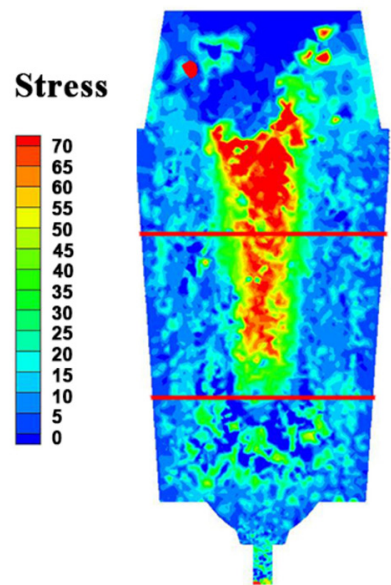

(b)
Fig. 10: (a) equivalent strain development in the longitudinal section within BTR, (b) equivalent stress development in the longitudinal section within BTR 
Experiment

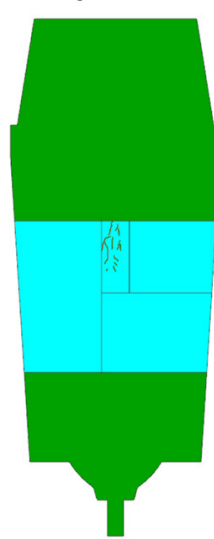

(a)

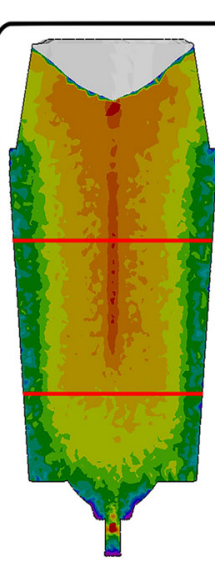

(b)

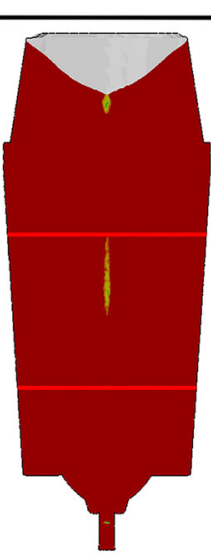

(c)

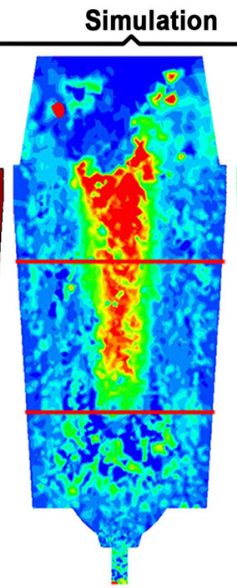

(d)

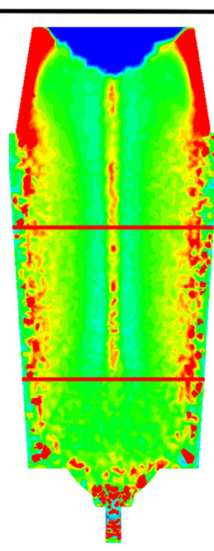

(e)

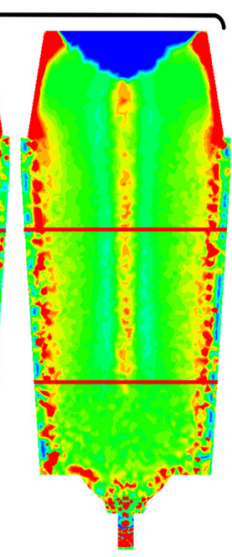

(f)

Fig. 11: (a) schematic diagram of crack-like defects in experiment, (b) shrinkage porosity in the longitudinal section of ingot, (c) Niyama values, (d) equivalent stress development within BTR, (e) HCS according to Clyne and Davies's criterion, (f) HCS according to Katgerman's criterion

\section{References}

[1] Chojecki A, Telejko I, and Bogacz T. Influence of chemical composition on the hot tearing formation of cast steel. Theoretical and Applied Fracture Mechanics, 1997, 27(2): 99 $-105$.

[2] Rappaz M, Drezet J M, Gremaud M. A new hot-tearing criterion. Metallurgical and Materials Transactions A, 1999, 30(2): 449-455.

[3] Won Y M, Yeo T, Seol D J, et al. A new criterion for internal crack formation in continuously cast steels. Metallurgical and Materials Transactions B, 2000, 31(4): 779-794.

[4] Drezet J M and Rappaz M. Prediction of hot tears in DC-cast aluminum billets. Light Metals: Proceedings of Sessions, TMS Annual Meeting (Warrendale, Pennsylvania), New Orleans, LA, United states, 2001, 887-893.

[5] Olivier C, Yvan C, and Michel B. Hot tearing in steels during solidification: Experimental Characterization and Thermomechanical Modeling. Journal of Engineering Materials and Technology, 2008, 130(2): 21018.

[6] Bellet M, Cerri O, Bobadilla M, Chastel Y. Modeling hot tearing during solidification of steels: assessment and improvement of macroscopic criteria through the analysis of two experimental tests. Metallurgical and Materials Transactions A, 2009, 40(11): 2705-2717.

[7] Ridolfi M R. Hot tearing modeling: a microstructural approach applied to steel solidification. Metallurgical and Materials Transactions B, 2014, 45(4): 1425-1438.

[8] M'Hamdi M and Mo A. Microporosity and other mushy zone phenomena associated with hot tearing. Light Metals: Proceedings of Sessions, TMS Annual Meeting (Warrendale, Pennsylvania), Seattle, WA, United states, 2002, 709-716.

[9] Hatami N, Babaei R, Dadashzadeh M, et al. Modeling of hot tearing formation during solidification. Journal of Materials Processing Technology, 2008, 205(1-3): 506-513.

[10] Suyitno S T, Kool W H, and Katgerman L. Hot tearing criteria evaluation for direct-chill casting of an $\mathrm{Al}-4.5 \mathrm{pctCu}$ alloy. Metallurgical and Materials Transactions A, 2005, 36(6): 15371546.

[11] Katgerman L. Mathematical model for hot cracking of aluminum alloys during D. C. casting. Journal of Metals, 1982, 34(2): 46-49.

[12] Guo $J$ and Zhu J Z. Prediction of hot tearing during alloy solidification. Proceedings of the 5th Decennial International Conference on Solidification Processing, 2007: 549-553.

[13] Eskin D G and Katgerman L. A Quest for a New Hot Tearing Criterion. Metallurgical and Materials Transactions A, 2007, 38(7): 1511-1519.

[14] Pequet C, Gremaud M, Rappaz M. Modeling of microporosity, macroporosity, and pipe-shrinkage formation during the solidification of alloys using a mushy-zone refinement method: Applications to aluminum alloys. Metallurgical and Materials Transactions A: Physical Metallurgy and Materials Science, 2002, 33(7): 2095-2106.

[15] Won Y M, Kim K, Yeo T, et al. Effect of cooling rate on ZST, LIT and ZDT of carbon steels near melting point. ISIJ International, 1998, 38(10): 1093-1099.

This work was financially supported by the National Basic Research Program of China (No. 2011CB012900) and the National Science NSFC-Liaoning Joint Fund (U1508215). 